\title{
The Assessment Process of Pupils’ Learning in Saudi Education System: A Literature Review
}

\author{
Yahya Al Alhareth ${ }^{1, *}$, Ibtisam Al Dighrir ${ }^{2}$ \\ ${ }^{1}$ Centre for Computing and Social Responsibility, De Montfort University, Leicester, UK \\ ${ }^{2}$ General Administration of Education in Najran region, Ministry of Education, Riyadh, Kingdom of Saudi Arabia \\ *Corresponding author: alhareth_y@yahoo.com
}

Received September 15, 2014; Revised September 30, 2014; Accepted October 08, 2014

\begin{abstract}
Assessments are essential components of teaching and learning programmes and help shape individual learning. Assessment at secondary and higher education levels in the Kingdom of Saudi Arabia (KSA) uses an examination system and it relies solely on the teacher to assess students. The assessment does not assess the ability of students to design and carry out experiments or even evaluate their understanding of mathematical and scientific concepts. Thereby, this paper will review the literature of the assessment process in the Saudi General Education System by considering several different aspects. This consideration will include the definitions and purpose of assessment as a means of learning about students and the progression of their learning. The different forms of assessment will also be considered as well the assessment practices in mathematics, and in particular in intermediate schools in Saudi Arabia as it can provide insights into the quality of assessment practices.
\end{abstract}

Keywords: summative assessment, formative assessment, assessment process, mathematics assessment

Cite This Article: Yahya Al Alhareth, and Ibtisam Al Dighrir, “The Assessment Process of Pupils' Learning in Saudi Education System: A Literature Review.” American Journal of Educational Research, vol. 2, no. 10 (2014): 883-891. doi: 10.12691/education-2-10-6.

\section{Introduction}

Education is important in any country that seeks to develop [5]. Education has been shown to contribute directly towards economic growth [7], and indeed, where countries are unable to provide suitable education systems, there is a direct link with poor economic growth (ibid). Therefore, it is important for stakeholders in every economy to ensure that their education system serves the intended purpose [5]. Education has been an important part of economic development in Saudi Arabia for a long time now [7]. For the education system to be effective it must produce students who meet the country's needs in terms of the skill base for economic development and the level of proficiency to be able to advance the country economically. Only a robust system of assessment can ensure that the education has been assimilated and embedded into the skill base of the country.

According to reference [47], various organisations in charge of knowledge acquisition find it difficult to conduct proper student assessment even after designing effective education systems. As a result, they end up having a wrong impression of student performance (ibid). In Saudi Arabia, any form of assessment aims at measuring the education curriculum's outcome [8]. However, it is a common belief that the curricula, facilities and teaching standards of the Saudi Arabian system do not match with the standards in education needed by a large and wealthy country such as Saudi
Arabia [7] and rely too much on rote learning [1]. References [2,3,4] believe that the Saudi education system focuses on subjects that students are not interested in and the reliance on rote learning leads to memorization rather than understanding. Therefore, the academic content is lacking and teaching and learning are narrowly focused on passing exams rather than developing deep understanding [2].

The examination system is used to assess student performance [8], but this has raised many doubts over its reliability $[7,8]$. In secondary, intermediate and primary schools, the approach to student examination is identical [7]. Teachers have no guidance on the examination [8] and textbooks do not publish examination instruments [6]. As a result, teachers design their own tests [8]. While, in some areas, the tests have served the intended purpose, it is believed that most of them have failed to give a true reflection of student performance [7], and this dilemma has been a subject of discussion among different researchers [8]. In Saudi Arabia, assessments come in the form of traditional (standardised) tests, which means that students usually do this type of test individually using paper and pencil to answer written questions which include gap fill, multiple choice, true or false and essays $[7,8]$. Researchers have constantly criticised this system [47]. According to reference [45], traditional assessment methods are not effective ways of testing the expanding learning concept, which requires students to exhibit thinking skills at a higher level than before. She further emphasises that traditional tests only assess a limited number of cognitive skills and functions associated with 
memory and the ability of students to remember information that they acquired out of context [ibid].

According to references [7-24], "teaching to test" is a common practice in Saudi schools. This limits student potential to developing skills at a low level and distorts the curriculum. This problem affects all subjects but is more emphatic in mathematics and sciences than in other subjects [6]. When students do a multiple-choice mathematical test, they may get the right answer by guessing or even taking the option closest to the answers they get from their calculations [ibid]. As a result, they develop low-level accuracy, which may affect their performance in technical careers such as Engineering [26-43]. Besides, educators in science and mathematics argue that traditional tests lack the capacity to assess the ability of students to design and carry out experiments or even evaluate their understanding of mathematical and scientific concepts. When they occur at the intermediary level, they affect pupil performance in both secondary and higher education levels [ibid]. Therefore, it is important to study the assessment processes in use at the intermediary levels as this can provide insights into the quality of assessment practices.

\section{Definition of Assessment}

According to reference [9], assessment refers to the process of examining and providing feedback on skills, knowledge, attitudes and work products in order to elevate or raise future learning outcomes and performances. Although people use assessment and "evaluation" interchangeably [45], there is a distinct difference between them. Evaluation aims at determining the level of performance, quality or outcome, and facilitates decision making according to the level of quality exhibited. Thus, while assessment improves future performance qualities, evaluation determines the quality attributed to the current performance. Such differences in meaning are found in feedback [15]. Reference [19], argues that while feedback in an assessment depends on observations and identifying the weakest and strongest points, evaluation feedback depends on the level of quality in relation to a standard. These two processes are vital in any education system because each one plays a vital, complementary role towards the other [ibid].

The assessment of students' achievements can be made at any point in the learning process by different individuals and for various reasons [15]. For example, teachers may assess children on a daily or weekly basis [27]. The assessments may take place through classroom quizzes or observations [19]. According to reference [19], the aim of such assessments is to help students monitor their progress. They also help teachers to identify weak points in their instruction according to student learning, and they can be used to motivate students. Principal, administrators and superintendents can use assessments to document individual district, school, classroom and, most importantly, student progress. In addition, they help both public and policy makers monitor the extent to which educational systems are effective. Assessment can also be used to motivate students [ibid].

According to reference [15], assessment is a communicative tool between the education circle and the rest of society. It exhibits a spectrum of ranges of communication from extremely informal to extremely formal exchanges. They constitute a wide range of things such as school reports and extend to high-value public examinations including job interviews, and national monitoring [ibid]. Whatever the assessment activity, the common factor is the assessment data that the wider public freely accepts as a code of exceptional quality [39].

\section{Purpose of Assessment}

Assessment of learning serves a number of purposes. As the Secretary of State for Education in the UK's expert group on assessment reported in 2009, assessment is carried out, firstly to optimise the effectiveness of the learning by pupils and the teaching of teachers, secondly to hold schools accountable for their performance, thirdly to supply information to parents about their child's progress, and finally to provide reliable and comparable information about standards nationally over time [18]. From the perspective of teachers the reasons for assessment are varied. In addition to the official reasons laid down by the national curriculum in the UK for example, teachers will give a number of additional reasons for assessing their pupils. These include such factors as:

- Identifying learners' needs,

- Planning learning such as deciding where to start on their teaching programme through initial assessment,

- tracking learner progress,

- diagnosing problems,

- helping learners improve,

- adjusting the pace or focus of learning,

- providing evidence of achievement,

- judging the effectiveness of a learning programme

- assessing their own teaching [38].

Therefore, there are many personal reasons for the teacher to undertake assessment of students' knowledge and understanding. Such assessment can be seen as a four step process:

1. setting up clear, measurable expected outcomes of student learning;

2. ensuring sufficient opportunities to achieve the outcomes for the student;

3. establishing the gap between teacher expectation and student learning through the systematic gathering, analyzing and interpretation of evidence

4. Using the findings to plan the next stage of learning to facilitate improvement.. This process is continuous since the final stage takes the teacher back to the first step [44].

Assessment is therefore mainly about gathering information of student learning and attainment which can then be used for a variety of purposes as outlined, since the teacher can analyse, interpret and make judgements on the learning of the students as well as of their own performance, as well as for external reporting or giving feedback to students [44].

When the purpose of assessment is to measure learning, there is social interaction between students and teachers and also between students. The assessment can be seen to help students understand their skills, strengths and weaknesses, the knowledge they have gained, and their abilities through feedback, and as such forms a natural part of the learning and teaching process which is key to 
supporting learning [10]. It is important that teachers can analyse and interpret the information from assessment, and apply these findings to adjusting and monitoring their own approaches to teaching [ibid]. This is also acknowledged by reference [9], who believes that assessment provides information on skills, knowledge and attitudes which teachers can use as a basis to improve the learning outcomes and future performance of their students.

\section{Forms of Assessment}

Assessment takes many different forms and it is the purpose of the assessment that determines the type of assessment carried out and the approach to that assessment [12]. The main forms of assessment include summative, norm-referenced tests, evaluation and accountability tests, diagnostic assessments and formative assessments [11,12]. Assessment normally takes place as formative or summative [44].

\subsection{Summative Assessment}

This form of assessment plays a vital role in the education process [39]. As a result, it is most visible in schools [11]. Teachers use it to measure the content that students have gained when a unit terminates [29]. This assessment also promotes students to guarantee that they have attained the expected standards before attaining school completion certificates [ibid]. One can also describe summative assessment as a means that concerned parties use to select students, who are eligible to pursue further education [ibid]. According to reference [39], summative assessments allow trainers and teachers to know the achievements a learner has accomplished in the course of study. Rust argues further that teachers subject their students to summative assessments towards or at the end of their course. The assessment uses a formal approach to investigate whether the learners or students have gained the skills, knowledge, understanding or behaviour that the course had planned to give them [29-45]. Sometimes, trainers and teachers are responsible for designing and marking the work, as well as ensuring that the activities they design conform to the curriculum, which usually are set by the governing or awarding body [12] as is the criteria for assessing the work. In other instances, the awarding body may dictate how the trainers and teachers should carry out the summative assessment. Summative assessments help students or learners to receive qualification awards such as grades, certificates and diplomas [39]. According to reference [39], these qualifications are important in the learners' lives because they help the learners to secure new employment or make changes to the current employment. The qualifications may also help others in their pursuit for education at a higher level [ibid]. Education ministries or departments may utilise summative assessments schools accountable for the quality of education through attainment by pupils [11]. Assessments working at the international level, for example, the Programme for International Student Assessment, which Organisation for Economic Cooperation and Development uses, have assisted in the comparison of a country's education system to developments taking place in other countries [45].

\subsection{Formative Assessment}

Unlike summative assessments, formative assessments play formative roles in the learning situation [12]. In the classroom situations, formative assessments are the frequently occurring interactive assessments of student understanding and progress to identify their learning needs while aiming at making appropriate teaching adjustments [11]. Reference [40] identifies three stages in formative assessment, namely the identification of a goal, working towards that goal, and then taking action to improve teaching and learning. Therefore, through assessing students to find out their level of understanding [48], formative assessments aim to both provide measurement of students' learning and assist the teacher to provide the most effective learning environment. They also serve to allow students to consolidate and appreciate their own understanding. In contrast summative assessments are intended to record overall achievements [23].

Formative assessment requires feedback, an indicator that a gap exists between the actual work level under assessment and the expected standard [12]. Feedback in this case usually refers to the gap existing between the actual work level and the level of reference of any system parameter, which helps to alter the gap in a particular manner [19]. It also involves suggesting what should happen to meet the expected standard (Pamrasad, 1983).The teachers and instructors utilising this form of assessment are in a good position for meeting the diversity of student needs [42]. They can achieve this by differentiating and adapting teaching to upgrade student achievement levels and enhance the equity of their outcomes [13].

However in wider practice, this form of assessment experiences various barriers [13], for example, the users can meet perceived tensions in the formative assessments taking place in the classroom situation. Typically these tensions include the conflict experienced by the student between being assessed, which involves retrospection or review of what they perceive to be subject matter already covered while their desire is to progress to new material and learning, so they perceive the assessment to be for the teacher's purpose and not their own [23]. The application of formative assessment principles can occur at policy and school levels [29] and embedding such assessment into school practices helps to identify areas that require more attention and promotes constructive and effective evaluation cultures throughout the entire education systems [19]. The more constructive use of formative assessment may help stakeholders to tackle the barriers hindering its wider take up within in the classroom [23].

References [13-29], categorise formative assessment further into formal and informal assessments. Formal, formative assessments are acts with prior plans, whose design provides evidence of students' learning [37]. These assessments may assume the form of assessments that are curriculum-embedded and focus on aspects of knowledge acquisition [23]. They may also involve quizzes, direct questioning, question generation and brainstorming among others [42]. Informal, formative assessments entail the generation of evidence during a teacher's daily classroom activities [29]. This assessment is improvisational and may occur during interaction between the teacher and the student [37]. The informal assessment process is flexible 
and unpredictable because teachers using them cannot predict the exact time, place, or manner in which opportunities to get assessment information arises [42]. Yet there is a very powerful pedagogical tool.

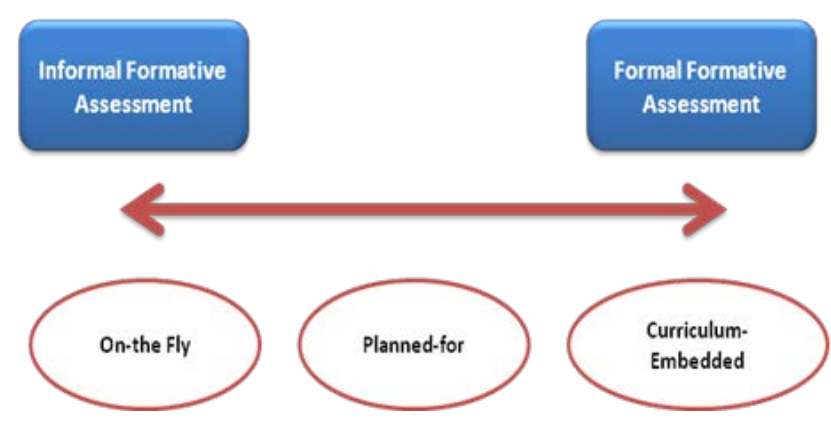

Figure 1. The formative assessment continuum [42]

It is possible to represent the continuum between informal and formal formative assessment as consisting of three categories: so called on-the-fly assessment, plannedfor assessment and curriculum-embedded assessment [42]. The figure below represents this continuum.

On-the-fly assessment occurs when assessment opportunities arise spontaneously in the classroom [42]. This teaching action blends well with daily teaching practice. In fact, it may sometimes appear to be a good teaching rather than an assessment [11]. Various opportunities to collect student information may arise repeatedly during lessons and teachers should take them as opportunities to conduct on-the-fly formative assessment [ibid].

Planned-for-interaction assessment lies at the centre of the continuum. It involves a deliberate plan by a teacher to carry out formative assessment [42]. Unlike on-the-fly assessment, planned-for formative assessment is always deliberate, but less formal than curriculum embedded assessments [14-42]. Rather than waiting for opportunities, teachers using planned-for assessments earlier in the course to plan the questions they will ask students in order to maximise their gaining of the information [ibid].

Curriculum embedded assessment is formal [12]. In this assessment, curriculum developers or teachers embed assessments to the current curriculum to create teachable opportunities or moments [ibid]. Embedding assignments usually occurs in a sequence of at least three lessons to clarify sub-goals vital in the achievement of unit goals [11-42]. This, in essence, presents opportunities for teaching in areas in which students face problems [bid].

It is worth mentioning that both formative and summative assessments have various subcategories, which are written, oral, product and performance assessments [46]. Each one of these assessments includes different forms as follows: multiple choices, true and false, matching, fill-in-the-blank, short answers, essay, and standardised exam are written assessments, while structured oral tests, one-to-one interviews and panel interviews are oral assessments. Simulation, presentation and role play are performance assessments, whilst product assessment forms are work samples, self-evaluation and portfolios [ibid].

\section{Effective Assessment Practice}

Assessment plays the central role of influencing the quality of learning and teaching in education systems [27]. As a result, the knowledge and adoption of effective assessment practice is a vital requirement in any education system [28]. Well-designed assessments possess characteristics such as the ability to set clear expectations, the ability to establish workload that is reasonable and the provision of opportunities for students to rehearse, self-monitor, practice and get feedback [27]. Effective education systems should ensure that assessments are integral components of logical, educational experiences [ibid]. Three main, interrelated objectives influence the achievement of quality assessment amongst students: First, the assessment should encourage and guide effective approaches towards learning. Secondly, the assessment should measure the expected outcomes of the learning process reliably and validly. Finally, the grading and assessment should define and protect academic standards [35].

There is limited awareness that assessment requirements, standards and clarity of the assessment criteria influence student learning effectiveness [35]. Assessment practices with appropriate designs directly influence the students' approaches towards their studies [27]. This implies that it has a direct and powerful contribution to quality in learning.

The common belief among students is that the requirements of an assessment literally define the curriculum [28]. Therefore, assessment is a powerful strategic tool that educators can utilise to spell out rewardbased learning and guide students towards developing effective study techniques [7]. However, it is worthy to remark that assessments with poor designs can potentially hinder the learning process or stifle the innovation of the curriculum [ibid].

There are various indicators of effective assessment methods [6]. First, the students and teaching fraternity treat it as a prominent and integral part of the whole process of teaching and learning, rather than a final attachment to the process [28]. In effective assessment practices, the multiple roles of an assessment are recognisable [7]. The potent motivating impact of assessment requirements on any student is clear and the design of assessment tasks fosters valuable study habits [28]. In addition, a policy exists to guide assessment practices among individual teacher [6]. Subject assessment occupies an integral part of the entire course assessment plan (ibid). Thirdly, a clear position exists between the expected outcomes from learning, what is learnt and taught, and the skills and knowledge assessed [7], which creates a coherent and closed 'curriculum loop'.

The assessment activities can measure the ability to analyse and create novel concepts and information rather than just recalling information that has featured in a previous presentation [28]. This ensures that creativity is part of the teaching and learning processes [7]. In addition, a wide range of assessment methods should be in use. This helps to minimise the limitations associated with assessment methods [ibid].

The design of various assessment tasks is such that they can assess appropriate generic skills and subject-specific skills and knowledge [28]. Such designs avoid any form of irrelevance while maximizing the effectiveness of the assessment process [7]. Effective assessment methods facilitate a steady development in the demands and 
complexity of assessment requirements during later course years [17]. This implies that they allow for progressive development, whose main purpose is to make assessment practices effective throughout the entire course.

Student choice is vital in any assessment task [28]. Thus, effective assessment practice ensures that provisions are available to ensure they cater for student choice. In addition, the design of an effective assessment method should consider all teaching and learning requirements [17]. Thus, during the design and scheduling of assessment tasks, the designers consider staff and student workloads. Such considerations play a significant role towards ensuring that the workload, in any instance, does not hinder the achievement of the assessment objectives [ibid]. Avoiding excessive assessment is a significant step towards enhancing assessment effectiveness [28]. Thus, in effective assessment practice, the design of the assessment tasks is such that they sample learning among students. This ensures that the assessment is effective [ibid].

In any effective assessment method, balancing judgmental (summative) and developmental (formative) roles of assessment is necessary [28]. Thus, effective assessment practices involve weighting assessment tasks to ensure there is a balance between summative and formative assessment roles [17]. It also involves providing feedback to students through effective methods (ibid). Effective grading also plays a vital role towards influencing effective assessment practice [28]. Grade calculation and reporting occur according to predetermined learning outcomes and the criteria determining the achievement levels. In addition, teachers should ensure students get diagnostic and explanatory feedback as well as their grades [7].

Where the student pool constitutes different groups, the likelihood of introducing various forms of bias is high [28]. Thus, in effective assessment practices, the teachers have to check the assessment tasks to ensure they have no biases and that they do not disadvantage any student group [6].

\subsection{Effective Assessment Practice in Mathematics Teaching}

Concerned parties should ensure a wide range of assessment methods is available to help teachers monitor the progress of their students [6]. This plays a vital role in their bid to comprehend mathematical concepts and develop sufficient mathematical skills [7]. The assessment of learning in mathematics should not be limited to standard tests whose applications occur intermittently. In addition, the learning environment ought to consider the improvement of learning as the main function of an assessment [ibid]. According to reference [35], the standards for school mathematics assessment define assessment as the process through which teachers gather information about a student's familiarity with, capability to use, and perception towards mathematics and ability to infer from that information for various purposes.

According to reference [28], effective assessment is not similar to a goal, but rather a means to achieving a goal. This implies that for assessment to add value to the society, it should improve education, rather than merely recording its status. The policy lists down three basic educational principles, which provide the foundation for assessment that can improve education [17]. They include the content principle, the equity principle and the learning principle [ibid]. The content principle articulates that an effective mathematical assessment method ought to reflect that mathematics is the most important subject that students should learn [28]. This implies that assessments should not only be learning opportunities for students, but also give them an opportunity to show the knowledge and skills they have. Although it occurs for various reasons, the main goal of assessment is to improve learning among students and help teachers to make informed instructional decisions [17]. As a result, it ought to be an integral part of the classroom activity in progress rather than a source of interruption [7].

The learning principle articulates that the assessment method ought to improve the learning in mathematics [17]. It should also improve good or effective instructional practice. The equity principle articulates that assessors should provide support for the opportunity that every student has towards learning important mathematics [5]. This implies that assessment should provide a means towards instilling growth. The growth ought to be towards great expectations rather than acting as a filter through which students lose the opportunity to gain important mathematical knowledge [ibid]. An equitable assessment gives every student a chance to demonstrate the mathematical power that he or she possesses [28]. The accomplishment of this requirement is possible only if an assessment uses multiple approaches, provides adaptations for special education and bilingual students, and any other adaptations that would be helpful to students having special needs [ibid].

Besides the three principles, it is also worthy of mention that, like in other subjects, effective mathematical assessments should be open [17]. Openness comes in three perspectives. First, the students or individuals under assessment should gain access to the assessment process information [28]. Secondly, teachers ought to participate actively in stages of the whole assessment process. Finally, the assessment ought to be open to modification or scrutiny. In addition, an effective mathematical assessment promotes valid inferences or conclusions about mathematical learning sessions [28]. The validity of an inference depends on adequate and relevant evidence [5]. The type and amount of evidence desired depends on the consequences associated with the inference. For instance, a teacher may utilise informal interviews to assess the students' understanding of place value and use the resulting information to draft plan for future learning activities [28]. However, large-scale, high-stake assessments may require more evidence and more advanced formal analysis of the evidence than the previous scenario. Thus, it is necessary to keep these principles in mind while designing or contemplating, developing, testing and implementing changes or variations in assessment strategies. Classroom teachers or other individuals participating in the assessment should be aware of this [ibid].

\subsection{Teachers' Perceptions of Assessment Practice}

There is a general view prevailing among a limited number of researchers that age and gender influence the perceptions of mathematics teachers towards the process 
of assessment of students learning and assessment practices in schools, reference [31] endeavoured to describe the nature of classroom assessment and grading practices. Their findings showed that female teachers were more interested in the assessment of students' achievement, and used it more frequently than their male counterparts did.

Reference [34] founds that the majority of secondary teachers used teacher constructed-tests to assess the achievement and performance of their students, but that most teachers consider the act of assessment as additional to their busy schedule. $70 \%$ of female teachers over $54 \%$ of male teachers viewed assessment tasks as extra requirements on their list of duties and did not consider them to be tools for the improvement of student performances and achievement.

Reference [30] showed through an examination of classroom assessment and grading in high schools in the United States that there was no link between teacher assessment practices, ability levels of students, subject matter and grade level. However, age has been shown to be a moderating factor influencing the attitudes of teachers towards their assessment practices. Teachers above the age of forty showed a much higher belief that assessment should be accompanied by grade assignment than teachers below the age of 35. Therefore perceptions and attitudes towards assessment practices of teachers may be age related [25].

The understanding that perceptions affect behaviour has attracted the interest of a number of researchers in the area of assessment practices. Reference [16] studies into of inservice teacher's perceptions of classroom assessment surmised that teachers perceive assessment to be interplay of a number of factors. They found that teachers below the age of 34 attached less value to classroom assessment and used standardized tests more often in their classroom practices. An analysis of gender as a moderating factor in teacher perception did not yield any meaningful results.

A wide range of psychological factors also affect teacher beliefs, behaviours and attitudes. These include social, cultural, age, gender and environmental factors. A case study conducted by reference [21] on the measurement of pre-service teacher assessment training revealed that pre-service teachers believe more strongly in standardised tests than classroom assessments. However, a wide range of factors comes into play in the examination of the moderating factors behind teacher perception of assessment procedures and principles.

Gender constitutes a mild moderating factor in general perception of mathematics teachers towards assessment procedures and practices. An examination of assessment producers among teachers in Ohio by reference [32] found that those teachers with 1-5 years of experience, in the bracket of 24-30 years of age reported using alternative assessments more often than those teachers with 25-31 years of experience within the age bracket of 50-65.

\section{The Assessment Process in Saudi Education System}

There is a close interlinking of teaching materials, classroom management skills, educational aims and educational assessment processes. Assessments are essential components of teaching and learning programmes and play a role in shaping individual learning. Assessment is used in Saudi Arabia to measure student attainment [8] using an examination system and is the only system of assessment used [7]. An internal exam is sat by students at the end of every term with the school year having two terms in all, and the results are used to assess progression to the next grade by combining $50 \%$ of each term's grades. This is done in all years of education from primary, intermediate to secondary school [8] Internal exams make up the remaining assessments and are set by teachers, who design their own assessments, within the constraints of resources available to them within their school. The grading system for all assessments in Saudi Education System as (Table 1) below:

Table 1. The grading system for all assessments in Saudi Education System [41]

\begin{tabular}{|l|l|}
\hline Grading & Numerical Average \\
\hline Excellent & 90 and above \\
\hline Very Good & 75 to 89 \\
\hline Good & 60 to 74 \\
\hline Fair & 50 to 59 \\
\hline Fail & 49 and below \\
\hline
\end{tabular}

\subsection{The Assessment Process in Primary and Secondary Schools}

In Saudi Arabia, primary and secondary education covers nine grades [3]. Each academic year comprises two terms, each carrying $50 \%$ of the mark [8]. Continuous assessments occur in the form of periodic tests in the term. They account for $30 \%$ of the mark [ibid]. In the secondary stage, the pass mark for science and social subjects is a minimum of $40 \%$ [7], while for other subjects, the pass mark is $50 \%$ [3]. In the primary stage the first and second grades, terminal examinations occur orally, with an exception of science and mathematics in which written examinations are used [ibid]. In the fourth and fifth grades, assessments come in the form of continuous assessments [20]. However, exceptions occur in Islamic songs, reading, Tajweed (Quran intonation), Holy Quran, Tauhid and Islamic law whose assessments take place orally [6]. Assessments in the sixth grade also occur in written form except in the holy Qur'an, which is assessed orally [20].

\subsection{The Assessment Process in Intermediate School}

The Saudi Arabian curriculum is rigid and prescriptive with no opportunity for teachers to develop or amend it. It is centrally controlled and oriented on academic subjects [8] with the national curriculum, education facilities, assessment, teachers, additional funding and administration controlled by the Ministry of Education. Reference [8] suggesting that it is characterised by insufficient professionalism in administration of assessments, curricula and data gathering, and he purports that the curriculum lacks performance standards, content and rigor, and is hampered by poor decision making because there is insufficient data to inform decision making. These factors severely affect the national assessment strategy of the Kingdom [7]. However there are those such as [8] who 
also accuses the Saudi curriculum for being wanting and not providing pupils with the necessary content to inform decision making, with little opportunity for teachers, parents and students to influence curriculum development. The lack of teacher involvement in curriculum development has resulted in this rigid and over prescriptive curriculum, and has reduced teachers to merely delivering prescribed content. Reference [8] suggests that this means the educational system itself can only be substandard.

Policy makers devise and implement national assessments to meet the country's needs. The main purposes are: diagnostic, to identify problems in learning and develop new strategies to help pupils meet educational goals; evaluative, to assess the grading of school performance; formative, to measure student performance compared to the set curriculum content, partially with the view of improving the future student performance; and summative, to systematically record student's performance and grade them [7].

According to reference [27], assessments at the intermediate level come in the form of internally administered school exams and are in both written and oral forms. The written forms include structured oral tests, essays and multiple-choice questions [ibid]. Some assessments are continuous while others come at the end of every term in both written and oral exams [7]. Oral exams mainly feature Qur'anic recitation. Thus, the design of the assessments ensures they meet both summative and formative purposes [37]. Every student sits for a single paper in each subject [27]. An academic year at this level constitutes two terms, with each term accounting for $50 \%$ of the total mark [6]. Continuous assessments (periodic tests) cover $30 \%$ of the marks with the remaining $70 \%$ covering the written examination at the end of every term. Forty percent is the lowest pass mark in both science and social subjects, while $50 \%$ is the pass mark in the remaining subjects [27].

\subsection{The Process of Mathematics Assessment in Intermediate Schools}

Mathematics assessment in Saudi Arabia's intermediate schools occurs in written form. The aim of the assessments is to evaluate the knowledge and skills that students have gained. For example, while the calculation of area, volume or perimeter demonstrates knowledge gained, the use of calculators, rulers or other mathematical instruments to solve a problem demonstrates skill [27]. Some assessments are continuous as the course advances while others come at the end of every course. Thus, the end of a term marks the end of a course. The mathematics teachers are always in full control of the assessments. They design the assessments according to the content they have given to their students [7]. Mathematics teachers mark and grade the written assessments and make appropriate judgments depending on their performance [6]. The students have an opportunity to see their grades and feedbacks, which help them to identify their weak points [46]. Sometimes, where a class constitutes many students, mathematics teachers face difficulties addressing student problems on an individual basis. To overcome this challenge, they identify where students have common problems and address them through discussions in the classroom situation. They also encourage students to discuss freely amongst themselves and consult whenever they are stuck [6]. This promotes the principle of equity. Mathematics teachers at the intermediary level encourage active participation because gaining mathematical knowledge and skills entails repetitive trials and feedbacks to ensure continuous learning [7].

The process of assessment used to assess pupils' learning in mathematics at intermediate level is divided into two terms each equally weighted $50 \%$ of total scores. Each term comprises 20\% continuous assessment, 30\% final exam. When students gain $40 \%$ over the two terms which is the lowest pass mark they are successful. The participation of students in class in for example mid-term quizzes, homework and extra activities, is assessed each term [33]. The assessment process of pupils' learning in mathematics as is shown (Table 2) below:

Table 2. The assessment process of pupils' learning in Mathematics [33]

\begin{tabular}{|c|c|c|c|c|c|c|}
\hline \multicolumn{5}{|c|}{ Academic Year } & Total & $\begin{array}{l}\text { Total } \\
\text { Score }\end{array}$ \\
\hline \multirow{5}{*}{ Term 1} & \multirow{4}{*}{$\begin{array}{l}\text { Continuous } \\
\text { Assessment }\end{array}$} & $\begin{array}{c}\text { mid-term } \\
\text { quizzes }\end{array}$ & $10 \%$ & \multirow{4}{*}{$20 \%$} & \multirow{5}{*}{$50 \%$} & \multirow{10}{*}{$100 \%$} \\
\hline & & Homework & $6 \%$ & & & \\
\hline & & Participation & $2 \%$ & & & \\
\hline & & Activities & $2 \%$ & & & \\
\hline & Final exam & \multicolumn{3}{|c|}{$30 \%$} & & \\
\hline \multirow{5}{*}{ Term 2} & \multirow{4}{*}{$\begin{array}{l}\text { Continuous } \\
\text { Assessment }\end{array}$} & $\begin{array}{c}\text { mid-term } \\
\text { quizzes }\end{array}$ & $10 \%$ & \multirow{4}{*}{$20 \%$} & \multirow{5}{*}{$50 \%$} & \\
\hline & & Homework & $6 \%$ & & & \\
\hline & & Participation & $2 \%$ & & & \\
\hline & & Activities & $2 \%$ & & & \\
\hline & Final exam & \multicolumn{3}{|c|}{$30 \%$} & & \\
\hline
\end{tabular}

\section{Conclusion}

The education system in Saudi Arabia constitutes four levels, namely primary, intermediate, and secondary and higher education. The structure of the academic year is similar in primary, intermediary and secondary levels. In all cases, teachers design and administer the assessments in the way they deem best. They provide grades and feedbacks to students to enable them identify their weak points and help them overcome them. Written and oral assessment is popular in all stages or education levels. The main modes of assessment in Saudi Arabia are written assessments and structured oral assessments. Each form of assessment has its own advantages and disadvantages, which teachers should know before using them. Mathematics assessments at the intermediate level in Saudi Arabian schools take place both continuously and at the end of every term. This ensures they serve both summative and formative purposes. Mathematics teachers design and administer the assessments, which occur in written forms; multiple choice questions or fill-in blanks. Effective mathematical assessments entail strict adherence to three principles of assessment: equity, learning and content principles.

Research shows that assessment should be wide ranging in order to provide a comprehensive view of student ability. Assessments should improve education and be part of the learning process rather than an interruption to it, 
and students should themselves learn from it. It should not be an interruption to the learning and be a goal in itself, as is currently the case in Saudi Arabia. Feedback should therefore form an important part of the assessment process for learning and this should be embedded in classroom teaching. Further, age and gender differences in attitudes can be seen worldwide and these can lead to disparity in the assessment of students, therefore teacher training needs to be examined and informed in order to create standardisation across the student experience. A shift in thinking may be needed in Saudi Arabia to develop attitudes in both teachers themselves and in the system of assessment in operation and to identify the variance in attitudes and practices.

\section{References}

[1] Abir, A., (1993), Saudi Arabia: Government, Society, and the Gulf Crisis, New York: Routledge.

[2] Al Kadri, H. M., Al-Moamary, M. S., Magzoub, M. E., Roberts, C. and van der Vleuten, C. P. M., (2011), Students' Perceptions Of The Impact Of Assessment On Approaches To Learning: A Comparison Between Two Medical Schools With Similar Curricula, International Journal of Medical Education, 2: pp. 4452.

[3] Al-Hakel, S., (2007), School Administration and its Manpower in Saudi Arabia (Riyadh, Saudi.

[4] Alhammad, T. M., (2010), The Education Dilemma in Saudi Arabia [online], The Harvard Crimson. Available at: http://www.thecrimson.com/article/2010/2/12/saudi-educationstudents-school/, [Accessed: 04-09-2014].

[5] Alromi, N., (2000), Vocational Education in Saudi Arabia, State College, PA: Penn State University.

[6] Alsadaawi, A., (2008), An Investigation of Performance-Based Assessment in Science in Saudi Primary Schools, Cambridge.

[7] Alsadaawi, A., (2010), Saudi National Assessment of Educational Progress (SNAEP), International Journal of Education Policy and Leadership, 5(11): pp. 1-14.

[8] Al-Sadan, I., (2000), Educational Assessment in Saudi Arabian Schools, Assessment in Education, 7 (1): pp. 143-155.

[9] Baehr, M., (2005), Distinctions between Assessment and Evaluation, Coe College, Faculty Guidebook, pp. 441-444.

[10] Berry, R., (2008), Assessment for Learning, Hong Kong: Hong Kong University Press.

[11] Black, P. \& William, D., (1998), Inside the Black Box: Raising Standards through Classroom Assessment, Phi Delta Kappan international, 80(2): pp. 139-148.

[12] Black, P. \& William, D., (2003), In Praise of Educational Research: Formative Assessment, British Educational Research Journal, 29: pp. 1-16.

[13] Black, P., (1998), Formative Assessment: Raising standards inside the classroom. School Science Review, 90(291): pp. 39-46.

[14] Black, P., Harrison, C., Lee, C., Marshall, B., \& Wiliam, D., (2002), Working Inside the Black Box: Assessment for learning in the classroom. London: King's College.

[15] Broadfoot, P., \& Black, P., (2004), 'Redefining assessment? The first ten years of assessment in education', Assessment in Education: Principles, Policy \& Practice, 11(1): pp. 7-26.

[16] Chester, C., and Quilter, S. M., (1998), In-service teachers' perceptions of educational assessment, Journal for Research in mathematics Education, 33(2): pp. 210-236.

[17] Darling-Hammond, L., (1994), Performance-based assessment and educational equity, Harvard Educational Review, 64(1): pp. 1-27.

[18] Department for Education (DfE), (2009), Report of the Secretary of State for Education Expert committee [online], United Kingdom, available at: http://publications.dcsf.gov.uk/eOrderingDownload/ExpertGroup-Report.pdf, [Accessed: 07-08-2014].

[19] Dochy, F., \& Segers, M., (2006), 'Enhancing Student learning Through Assessment: Alignment between Levels of Assessment and Different Effects on learning,' Studies in Educational Evaluation, Belgium, 32: pp. 171-179.
[20] Earl, L., (2003), Assessment as learning: Using classroom assessment to maximize student learning. Thousand Oaks, CA: Corwin.

[21] Green, K. E., (1992), Differing options on testing between preservice and in-service teachers, Journal of Educational Research, 86(1), 37-42.

[22] Harlen, W. and James, M., (1997), Assessment and Learning: Differences and Relationships between Formative and Summative Assessment, Assessment in Education: Principles, Policy \& Practice, 4(3): pp. 365-379.

[23] Herman, J., \& Choi, K., (2008), Formative Assessment and the Improvement of Middle School Science Learning: The Role of Teacher Accuracy, Los Angeles, University of California.

[24] Izard, J., (2004), Gathering evidence for learning: Paper presented at the Annual Conference of the Australian Association for Research in Education (AARE) Melbourne.

[25] Kadzamira, E. C., and Chibwana, M. P, (2000), Gender and primary schooling in Malawi, IDS Research Report, 40, Brighton: Institute of Development Studies.

[26] Laker, E., (1996), what the research says about student assessment [online], Improving America's Schools: A Newsletter on Issues in School Reform: the U.S. Department of Education, available at: http://www2.ed.gov/pubs/IASA/newsletters/assess/pt4. html, [accessed: 08-07-2014].

[27] Linn, M. A., (2008), 'Library and information science education in Saudi Arabia,’ Education for Information, 14(3): pp. 195-214.

[28] Mathematical Sciences Education Board (MSEB), National Research Council, (1993), Measuring What Counts: A Conceptual Guide for Mathematics Assessment. Washington, DC: The National Academies Press.

[29] McAlpine, M (2002), Principles of Assessment, Robert Clark Centre for Technological Education, University of Glasgow.

[30] McMillan, J. H., (2001), Secondary teachers' classroom assessment and grading practices, Educational Measurement Issues and Practice, 20(1): pp. 20-32.

[31] McMillan, J.H., Myran, S., \& Workman, D., (2002), Elementary teachers' classroom assessment and grading practices, Journal of Educational Research, 95(4): pp. 203-213.

[32] Mertler, C.A. (1998). Classroom assessment practices of Ohio teachers. Conference paper: EDRS

[33] Ministry of Education (MOE), (2011), the mechanism of testing for intermediate and secondary stages [online], Saudi Arabia, available at

http://portal.moe.gov.sa/Documents/ Mechanism\%20tests.pdf [accessed: 10-08-2014].

[34] Morgan, C., and Watson, A., (2002), The interpretative nature of teachers' assessment of students' mathematics: Issues for Equity, Journal for Research in mathematics Education, 33(2): pp. 78-110.

[35] National Council of Teachers of Mathematics (NCTM), (1995), Assessment Standards for School Mathematics, Reston, VA.

[36] Newby, P., (2010), Research methods for Education, Harlow, Essex, Pearson Education Ltd.

[37] Pamrasad, A., (1983), 'On the definition of feedback,' Behavioural Science, 28: pp. 4-13.

[38] Petty, G., (2004), Teaching Today Practical approach, $3^{\text {rd }}$ Ed., London: Nelson Thornes.

[39] Rust, C., (2002), Purposes and Principles of Assessment, Oxford Brooks University

[40] Sadler, D., (1989), Formative assessment and the design of instructional systems Instructional Science, 18: pp. 119-144.

[41] Saudi Arabian Cultural Mission (SACM), (2010) Grading System in Saudi General Educational System [online], Saudi Arabian Cultural Mission, Washington, DC., available at http://www.sacm.org/Education/GradingEdu.aspx, [Accessed: 1207-2014].

[42] Shavelson, R.J., \& the Stanford Education Assessment Laboratory [SEAL], (2003), On the integration of Formative Assessment in Teaching and Learning with Implications of Teacher Education, Paper Presented at the Biannual Meeting of the European Association for Research on Learning and Instruction. Padova, Italy.

[43] Shepard, L. A., Flexer, R. J., Hiebert, E. H., Marion, S. F., Mayfield, V., \& Weston, T. J., (1996), Effects of introducing classroom performance assessments on student learning, Educational Measurement: Issues and Practice, 15(3): pp. 7-18.

[44] Suskie, L. A., (2009), Assessing Student Learning: A Common Sense Guide, $2^{\text {nd }}$ Ed., Sanfrancisco, CA: John Wiley and Sons. 
[45] Taras, M., (2005), Assessment: Summative and Formative-Some Theoretical Reflections, British Journal of educational Studies, University of Sunderland, Blackwell Publishing Ltd, 53(4): pp. 466-478.

[46] Van, K., Amichand, S., Carkner, M., Ireland, M., Orynik, K., and Potter, J., (2007), Quality Assurance in PLAR: Issues and
Strategies for Post-secondary Institutions, Quality Assurance in PLAR, volume 1.

[47] Verman, J., Aschbacher, P., \& Winters, L., (2008), 'A practical guide to alternative assessment,' ERIC Document Reproduction Service No.ED352389.

[48] Webber, C. F., and Lupart, J. L., (2011) Leading Student Assessment, London: Springer. 